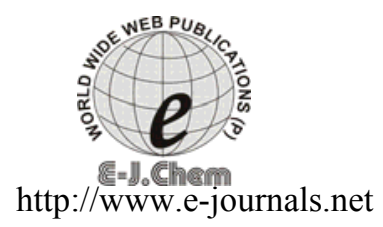

ISSN: 0973-4945; CODEN ECJHAO

E-Journal of Chemistry

2011, 8(S1), S61-S66

\title{
Biosorption Studies for the Removal of Malachite Green from its Aqueous Solution by Activated Carbon Prepared from Cassava Peel
}

\author{
C.PARVATHI ${ }^{*}$, T.MARUTHAVANAN, S.SIVAMANI ${ }^{\S}$ and C.PRAKASH ${ }^{\#}$ \\ *Department of Chemistry, Maha College of Engineering \\ Minnampalli, Salem-636 106, Tamilnadu, India \\ Department of Chemistry, SONASTARCH \\ Sona College of Technology, Salem-636 005, Tamilnadu, India \\ ${ }^{\S}$ Department of Biotechnology \\ Vinayaka Mission's Kirupananda Variyar Engineering College \\ Vinayaka Missions University, Salem - 636 308, Tamilnadu, India \\ "Department of Fashion Technology \\ Sona College of Technology, Salem-636 005, Tamilnadu, India \\ dearparvathi@rediffmail.com
}

Received 10 February 2011; Revised 16 April 2011; Accepted 28 April 2011

\begin{abstract}
The association of dyes with health related problems is not a new phenomenon. The effectiveness of carbon adsorption for dye removal from textile effluent has made it an ideal alternative to other expensive treatment methods. The preparation of activated carbon from agricultural waste could increase economic return and reduce pollution. Cassava peel has been used as a raw material to produce activated carbon. The study investigates the removal of malachite green dye from its aqueous solution. The effects of condition such as adsorbent dosage, initial dye concentration, $\mathrm{pH}$ and contact time were studied. The adsorption capacity was demonstrated as a function of time for malachite green from aqueous solution by the prepared activated carbon. The results showed that as the amount of the adsorbent was increased, the percentage of dye removal increased accordingly. Higher adsorption percentages were observed at lower concentrations of malachite green dye. Silver nitrate treated cassava peel showed a better performance compared to Sulphuric acid treated and raw carbons, thus making it an interesting option for dye removal textile effluent.
\end{abstract}

Keywords: Malachite green, Adsorption, Cassava peel, Activated carbon 


\section{Introduction}

The textile industry is, in the forefront, in the use of dyes in its operations ${ }^{1}$ with more than 9,000 types of dyes incorporated in the colour index. Similarly, more than 70,000 tons of approximately 10,000 different types of dyes and pigments are produced annually worldwide, of which $20-30 \%$ are wasted in industrial effluents during dyeing and finishing processes in the textiles industries ${ }^{2}$.

Dyes used in the textile industry are particularly difficult to remove by the conventional waste treatment methods because of their stability towards light and oxidizing agents and resistance towards aerobic digestion. For removal of colour from industrial wastewater, adsorption has become one of the most economic and effective methods ${ }^{3-7}$. The activated carbon adsorption treatment has been proven to be an effective replacement for the combined biological and chemical treatment although at a relatively high cost. The need of low cost replacements for activated carbon initiated a number of studies ${ }^{8}$.

Adsorption process is one of the effective methods for removal of dyes from textile effluent. Since commercially available activated carbon is very expensive, now the research is focusing on the use of low cost adsorbents derived from agricultural and wood wastes, such as bagasse ${ }^{9}$, coir $_{\text {pith }}{ }^{10}$, banana pith ${ }^{11}$, tree fern ${ }^{12}$, rice husk ${ }^{13}$ etc. This investigation is aimed at examining the capacity and efficiency of dye removal from aqueous solution by activated carbon prepared from cassava peel. The effects of initial dye concentration, contact time, $\mathrm{pH}$ and carbon dosage are also assessed.

\section{Experimental}

The cassava peel was collected from the nearby sago industry in Salem District, Tamilnadu, India. Then it was washed thoroughly with water to get rid of dust particles. Then it was dried under the direct sunlight to remove the excess moisture. Then the dried peel was placed in a muffle furnace (Naber, Germany, Model: L51/S) for $24 \mathrm{~h}$ at $150{ }^{\circ} \mathrm{C}$ and this material is used as raw cassava peel carbon.

\section{Silver nitrate treated cassava peel carbon}

A part of the above carbon was ground to powder and then treated with $0.5 \mathrm{~N} \mathrm{AgNO}_{3}$ solution (1:1) for $8 \mathrm{~h}$. Then the carbon was washed several times to remove excess $\mathrm{AgNO}_{3}$ present in it. Then the dried peel was placed in a muffle furnace for $24 \mathrm{~h}$ at $150{ }^{\circ} \mathrm{C}$ and this material is used as Silver nitrate treated cassava peel carbon.

\section{Sulphuric acid treated cassava peel carbon}

Other part of raw cassava peel carbon was ground to powder and then mixed with concentrated sulphuric acid (1:1). Then the carbon was washed with distilled water and soaked in $1 \%$ sodium bicarbonate solution overnight to remove residual acid. The material was dried in a muffle furnace for $24 \mathrm{~h}$ at $150{ }^{\circ} \mathrm{C}$ and this material is used as sulphuric acid treated cassava peel carbon.

\section{Preparation of adsorbate}

The malachite green is a green coloured, basic cationic dye (Chemical formula: $\mathrm{C}_{52} \mathrm{H}_{54} \mathrm{~N}_{4} \mathrm{O}_{12}$, Molecular Weight $=927.00, \lambda_{\max }=617 \mathrm{~nm}$ ). An accurately weighed quantity of malachite green dye was dissolved in double distilled water to prepare the stock solution with a concentration of $500 \mathrm{mg} / \mathrm{L}$. The stock solution was then properly wrapped with aluminium foil and stored in a dark place to prevent direct sunlight, which may cause decolourisation. Experimental solutions of the desired concentration were obtained by successive dilutions. 


\section{Batch biosorption studies}

\section{Effect of contact time}

$150 \mathrm{~mL}$ of dye solution with initial dye concentration $(50 \mathrm{mg} / \mathrm{L})$ was prepared in a conical flask with adsorbent concentration $(0.5 \mathrm{~g} / 150 \mathrm{~mL})$ and kept inside the incubator shaker (Environmental orbital Shaker Incubator, Deneb Instruments) at $120 \mathrm{rpm}$ and $27{ }^{\circ} \mathrm{C}$. Dye concentration was estimated spectrophotometrically at the wavelength corresponding to maximum absorbance, $\lambda_{\max }$, using a spectrophotometer (JASCO UV/Vis-550). The sample was withdrawn from the shaker at predetermined time intervals. The dye solution was separated from the adsorbent by bench top centrifuge (Remi Laboratory Instruments, R41) and the absorbance of solution is measured. The dye concentration is to be measured after 15, 30, 45, 60, 90 and 120 $\mathrm{min}$ for the equilibrium to be attained. The equilibrium adsorption capacity $\left(\mathrm{q}_{\mathrm{e}}\right)$ is expressed as

$$
\mathrm{q}_{\mathrm{e}}=\frac{\mathrm{C}_{0}-\mathrm{C}_{\mathrm{e}}}{\mathrm{X}}
$$

Where, $\mathrm{q}_{\mathrm{e}}=$ Amount of dye adsorbed per unit mass of adsorbent at equilibrium (mg/g). $\mathrm{C}_{0}=$ Initial dye concentration $(\mathrm{mg} / \mathrm{L}) . \mathrm{C}_{\mathrm{e}}=$ Final dye concentration $(\mathrm{mg} / \mathrm{L}) . \mathrm{X}=$ Dose of adsorbent $(\mathrm{g} / \mathrm{L})$.

\section{Effect of initial dye concentration}

$250 \mathrm{~mL}$ of dye solution was prepared in conical flasks with a dye concentration of $50 \mathrm{mg} / \mathrm{L}$ and adsorbent dose $(0.5 \mathrm{~g} / 150 \mathrm{~mL})$ and kept inside the incubator shaker at $120 \mathrm{rpm}$ and $27^{\circ} \mathrm{C}$. The final dye concentration readings were taken at corresponding equilibrium time. The final concentration of dye was measured using a spectrophotometer. The same procedure was followed for concentrations of 100, 150, 200 and $250 \mathrm{mg} / \mathrm{L}$.

\section{Effect of initial $p H$}

$150 \mathrm{~mL}$ of dye solution was prepared in a conical flask with dye concentration of $50 \mathrm{mg} / \mathrm{L}$ and adsorbent dose of $0.5 \mathrm{~g} / 150 \mathrm{~mL}$ and initial $\mathrm{pH}$ of the conical flask is to be measured. The $\mathrm{pH}$ of the dye solutions was adjusted to different $\mathrm{pH}$ values of $3,5,7,9$ and 11 with dilute $\mathrm{HCl}$ $(0.05 \mathrm{~N})$ or $\mathrm{KOH}(0.05 \mathrm{~N})$ solution and the value was measured by using a $\mathrm{pH}$ meter (Eutech Instrument, $\mathrm{pH} 510$ ). The prepared solutions were kept inside the incubator shaker at $120 \mathrm{rpm}$ and $27{ }^{\circ} \mathrm{C}$. The final concentration of dye was measured using a spectrophotometer.

\section{Effect of adsorbent dose}

$150 \mathrm{~mL}$ of dye solution was prepared in different conical flasks with dye concentration of $50 \mathrm{mg} / \mathrm{L}$ and adsorbent doses of $0.5,1,2,5,8 \mathrm{~g} / 150 \mathrm{~mL}$. The solutions were kept inside the incubator shaker at $120 \mathrm{rpm}$ and $27{ }^{\circ} \mathrm{C}$. The final concentration of dye was measured using a spectrophotometer.

\section{Results and Discussion}

\section{Effect of initial dye concentration}

The influence of the initial concentration of malachite green in the solution on the rate of adsorption on silver nitrate treated, sulphuric acid treated and raw cassava peel carbons were studied. The experiments were carried out at fixed adsorbent dose $(0.5 \mathrm{~g} / 150 \mathrm{~mL})$ in the test solution, $27{ }^{\circ} \mathrm{C}$ room temperature, $\mathrm{pH}(7.0)$ and at different initial concentrations of malachite green $(50,100,150,200$ and $250 \mathrm{mg} / \mathrm{L})$ for different time intervals $(15,30,45,60$, 90 and $120 \mathrm{~min}$ ). Result indicating the effect of initial methyl red concentration on the dye adsorption with contact time is shown in Table 1. 
Table 1. Effect of initial methyl red concentration on the dye adsorption with contact time

\begin{tabular}{ccccccc}
\hline Initial dye & \multicolumn{7}{c}{ Percent dye removal with time, min } \\
\cline { 2 - 7 } concentration, mg/L & 15 & \multicolumn{7}{c}{30} & 45 & 60 & 90 & 120 \\
\hline \multicolumn{7}{c}{ Silver nitrate treated cassava } \\
50 & 90.3 & 92.7 & 93.0 & 93.0 & 93.0 & 93.0 \\
100 & 89.7 & 90.4 & 91.0 & 91.0 & 91.0 & 91.0 \\
150 & 85.4 & 87.4 & 89.2 & 89.2 & 89.2 & 89.2 \\
200 & 78.2 & 81.1 & 84.2 & 84.2 & 84.2 & 84.2 \\
250 & 70.6 & 73.8 & 78.7 & 78.7 & 78.7 & 78.7 \\
50 & Sulphuric acid treated cassava peel carbon & & \\
100 & 77.4 & 78.8 & 80.6 & 82.7 & 82.7 & 82.7 \\
150 & 66.8 & 68.4 & 69.8 & 70.9 & 70.9 & 70.9 \\
200 & 57.8 & 58.9 & 60.9 & 61.7 & 61.7 & 61.7 \\
250 & 44.9 & 48.9 & 50.7 & 52.6 & 52.6 & 52.6 \\
50 & 24.7 & 28.9 & 30.8 & 32.8 & 32.8 & 32.8 \\
100 & 43.3 & Raw cassava peel carbon & & & \\
150 & 38.8 & 42.7 & 45.9 & 46.6 & 47.7 & 47.7 \\
200 & 36.7 & 40.9 & 43.8 & 44.7 & 46.8 & 46.8 \\
250 & 30.7 & 33.3 & 36.9 & 37.5 & 37.9 & 37.9 \\
& 25.6 & 26.9 & 28.4 & 29.6 & 30.8 & 30.8 \\
\hline
\end{tabular}

It is evident that the percent adsorption efficiency of silver nitrate treated, sulphuric acid treated and raw cassava peel carbons decreased with the increase in initial dye concentration in the solution. However, for silver nitrate treated and sulphuric acid treated cassava peel, equilibrium was achieved only after 60 and $90 \mathrm{~min}$, respectively. This may be due to the fact that silver nitrate treated and sulphuric acid treated cassava peel has macro and meso pores, resulting in longer contact time between the dye molecules and the adsorbent. In the process of dye adsorption, initially dye molecules have to encounter the boundary layer effect before diffusing from boundary layer film onto adsorbent surface. This is followed by the diffusion of dye into the porous structure of the adsorbent. This phenomenon will take relatively longer contact time. The time profile of dye uptake is a single, smooth and continuous curve leading to saturation, suggesting the possible monolayer coverage of dye on the surface of the adsorbent ${ }^{14}$. From Figure 1, it is evident that the dye adsorption is higher than silver nitrate treated cassava peel carbon than sulphuric acid treated and raw cassava peel carbons.

\section{Effect of adsorbent dose}

The adsorption of Malachite green on silver nitrate treated and sulphuric acid treated cassava peel carbons were studied by changing the quantity of adsorbent $(0.5,1,2,5,8 \mathrm{~g} / 150 \mathrm{~mL})$ in the test solution while keeping the initial dye concentration $(50 \mathrm{mg} / \mathrm{L})$, temperature $\left(27^{\circ} \mathrm{C}\right)$ and $\mathrm{pH}$ (7.0) constant. Experiments were carried out at different contact time.

As shown in Figure 2, the percent adsorption increased with increasing adsorbent dose. The adsorption increased from 48.9 to $94.1 \%$, as the Silver nitrate acid treated dose was increased from $0.2 \mathrm{~g}$ to $1.0 \mathrm{~g} / 150 \mathrm{~mL}$ at equilibrium time $120 \mathrm{~min}$ ). For sulphuric acid treated cassava peel, adsorption increased from 36.4 to $83.1 \%$ as the adsorbent dose was increased from 0.2 to $1.0 \mathrm{~g} / 100 \mathrm{~mL}$. Maximum dye removal was achieved within $90-120$ min after which malachite green concentration in the test solution was almost constant. Increase in the adsorption with adsorbent dose can be attributed to the increase in adsorbent surface area and availability of more adsorption sites. 


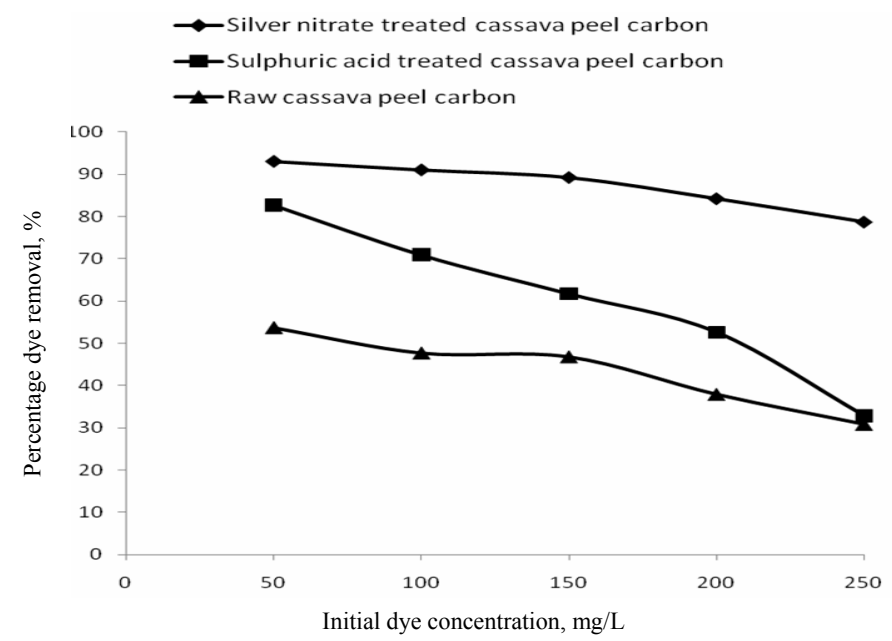

Figure 1. Effect of initial methyl red concentration on the dye adsorption

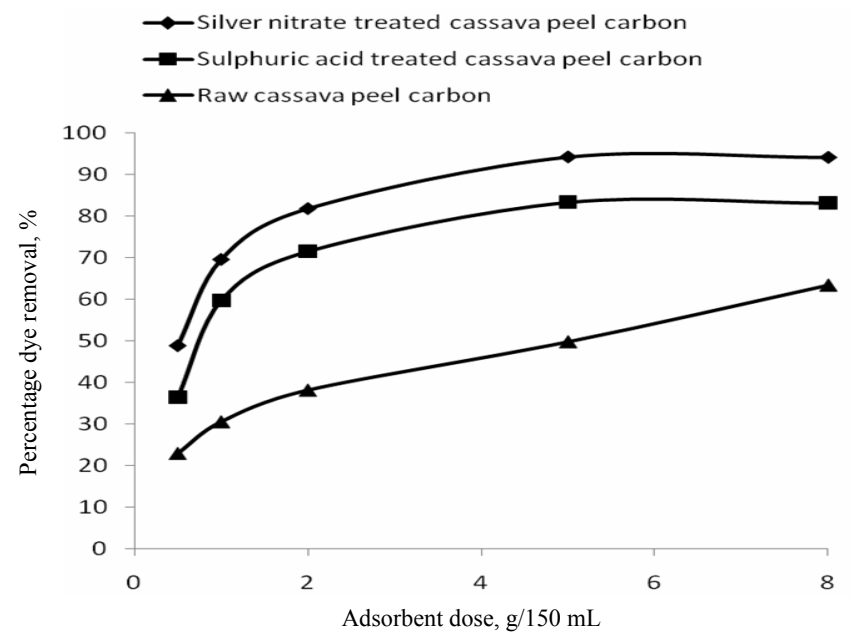

\section{Effect of $p H$}

Figure 2. Effect of adsorbent dose on the dye adsorption

In order to study the effect of $\mathrm{pH}$ on malachite green adsorption on silver nitrate treated cassava peel and sulphuric acid treated cassava peel, experiments were carried out at $50 \mathrm{mg} / \mathrm{L}$ initial dye concentration with $0.5 \mathrm{~g} / 150 \mathrm{~mL}$ adsorbent mass at room temperature of $27{ }^{\circ} \mathrm{C}$. Results are presented in Figure 3. In the case of raw cassava peel carbon, maximum dye removal of $59.6 \%$ was recorded at $\mathrm{pH} 11$. Between $\mathrm{pH}$ range of 2-7, the percentage of dye removal was nearly equal. Significant increase in dye removal efficiency for sulphuric acid treated cassava peel was observed between $\mathrm{pH}$ ranges from 3 to 7 . Although dye adsorption efficiency for Silver nitrate treated cassava peel is higher than the untreated and sulphuric acid treated cassava peel, it was not significantly affected by $\mathrm{pH}$. This may be due to hydrolysis of the adsorbent in water, which creates positively charged $\operatorname{sites}^{14}$. Overall, the dye adsorption by silver nitrate treated was $79-96 \%$ in the studied $\mathrm{pH}$ range followed by sulphuric acid treated (75-89\%) and raw cassava peel (44-60\%). 


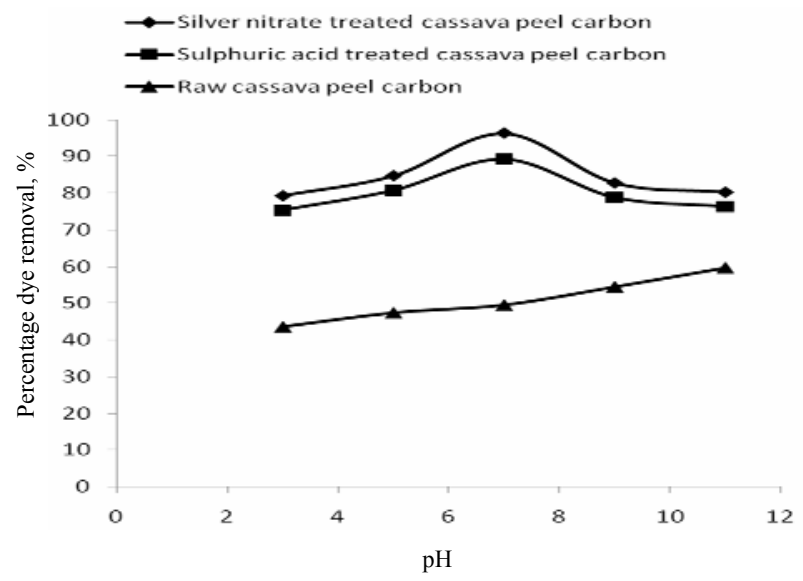

\section{Conclusion}

Figure 3. Effect of $\mathrm{pH}$ on methyl red adsorption

Activated carbons in different forms have a great role in modern life and help in providing energy efficient and trouble free living in clean environment. Cassava peel is a common biomass waste material and is easily available at low to negative costs. The removal of malachite green from simulated wastewater using chemical treatment of cassava peel with sulphuric acid and silver nitrate has been investigated under different experimental conditions in batch mode. The adsorption of methyl red was dependent on the contact time, adsorbent dose and initial Malachite green concentration in the wastewater. The results show that as the amount of the adsorbent was increased, the percentage of dye removal increased accordingly. Higher adsorption percentages were observed at lower concentrations of malachite green. Silver nitrate treated cassava peel showed a better performance compared to sulphuric acid treated cassava peel. This study proved that cassava peel is an attractive option for dye removal from dilute industrial effluents.

\section{References}

1. Garg V K, Gupta R, Yadav A and Kumar K, Biores Technol., 2003, 89, 121.

2. Kannan N and Meenakshisundaram M, Water Air Soil Poll, 2001, 138, 289-305.

3. Mckay G, Allen S J, Mcconvey I F and Otterburn M S, J Colloid Interface Sci., 1981, 80(2), 323-339.

4. Mckay G, J Chem Tech Biotechnol., 1983, 33A, 205.

5. Mckay G and Allen S J, Can J Chem Eng., 1980, 58, 521.

6. Mckay G and Mcconvey I F, J Chem Tech Biotechnol., 1981, 31, 401-408.

7. Nassar M M and Magdy Y H, Indian Chem Eng., 1999, 40(1), 27-30.

8. Vera Mesko, Liljana Markovska, Mineeva M and Doneo Burevski, Bull Chem Technol Macedonia, 2001, 20, 143-150

9. Valix M, Cheung W H and McKay G, Chemosphere, 2004, 56(5), 493-501.

10. Namasivayam C and Kavitha D, Dyes Pigments, 2002, 54, 47-58.

11. Kadirvelu K, Kavipriya M, Karthika C, M. Radhika, Vennilamani N and Pattabhi N S, Biores Technol., 2003, 87, 129.

12. Ho Y S, Biores Technol., 2005, 96(11), 1292-1296.

13. Malik P K, Dyes Pigments, 2003, 56(3), 239-249.

14. Garg V K, Amita M, Kumar R and Gupta R, Dyes Pigments, 2004, 63(3), 243-250. 


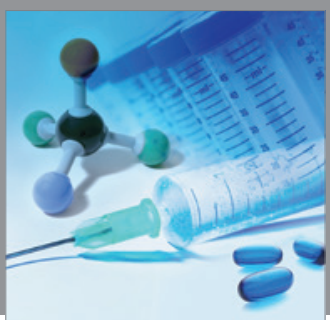

International Journal of

Medicinal Chemistry

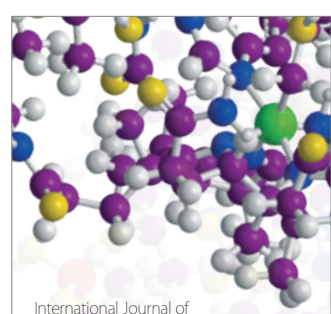

Carbohydrate Chemistry

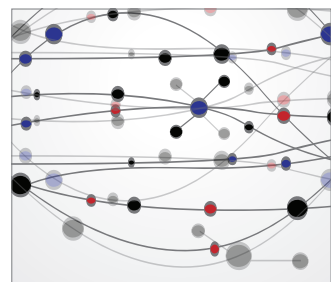

The Scientific World Journal
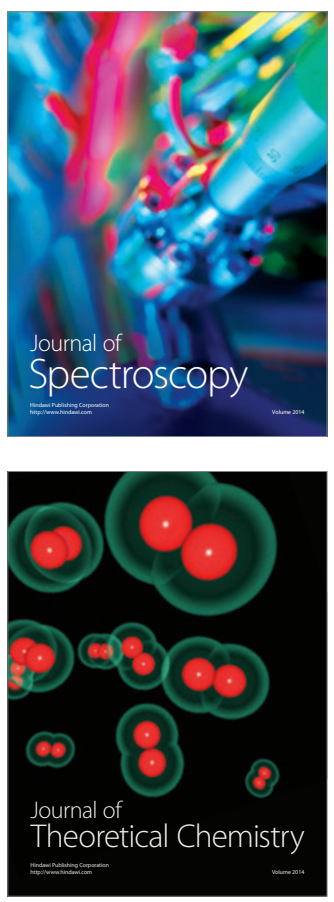
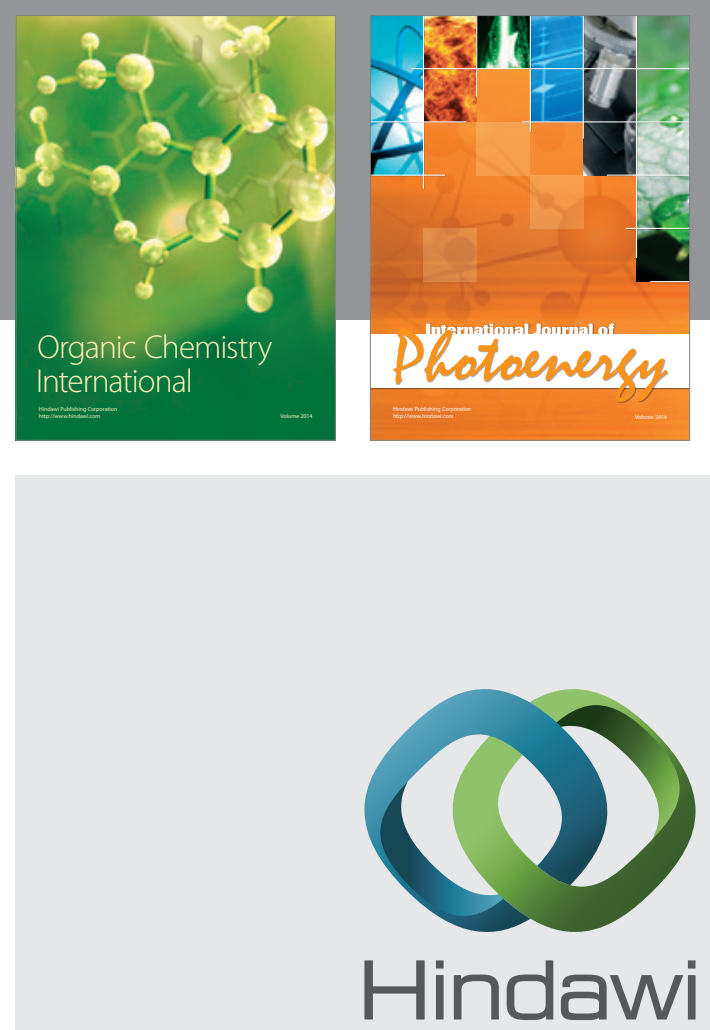

Submit your manuscripts at

http://www.hindawi.com
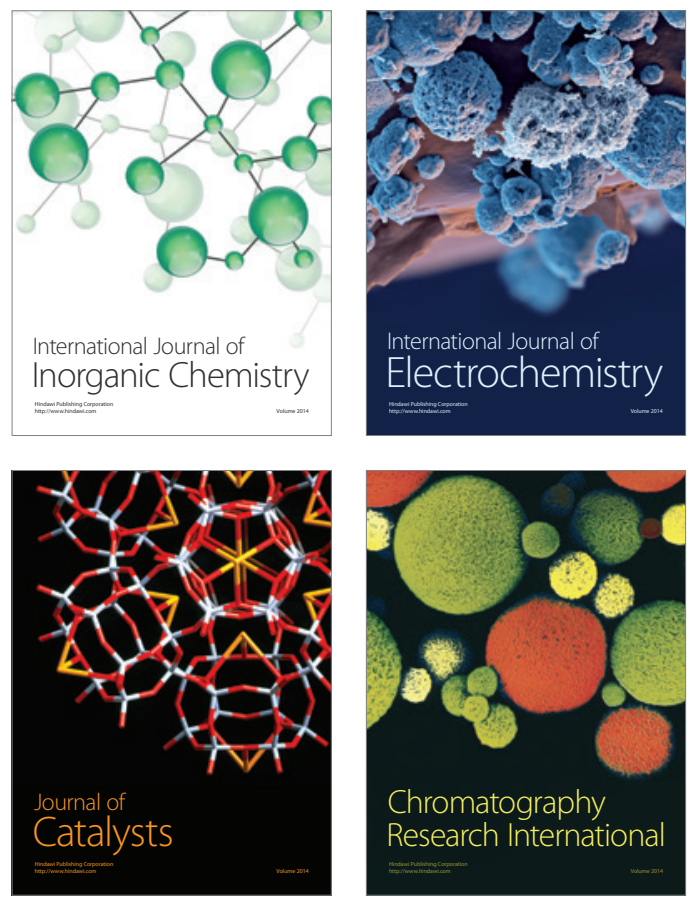
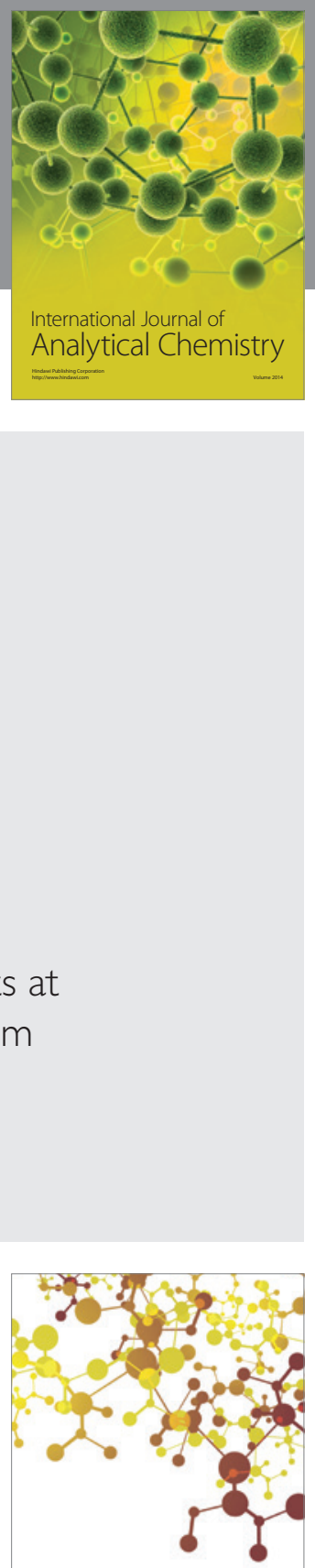

Journal of

Applied Chemistry
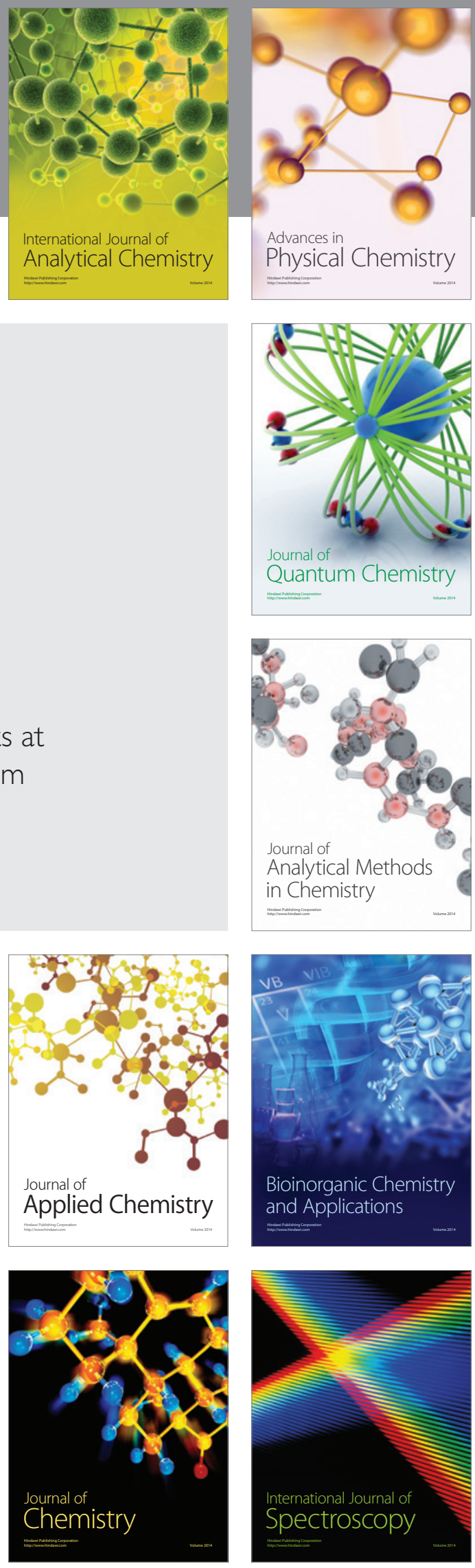